\title{
Chapter 7 \\ Alternative Techniques and Options for Risk Reduction of Gene Drives
}

\author{
Bernd Giese, Arnim von Gleich and Johannes L. Frieß
}

\section{Introduction}

With the release of organisms carrying a gene drive (GD) a fundamental change in the release practice of GMOs will take place. GMOs as GD-carrying organisms (GDO) will then arise from wild populations in the field, not in controlled numbers in the laboratory or a breeding facility (Simon et al. 2018). The inherent ability of GDs to overcome the limits of Mendelian inheritance even for traits with detrimental effects on their fitness make them an ideal tool for the efficient manipulation of wild populations of sexually reproducing species. The idea of using GDs was originally inspired by the discovery of naturally occurring mechanisms like transposable elements or meiotic drives that trigger a super-Mendelian dissemination of traits. After early proposals to harness chromosomal translocations for population control (cp. Curtis 1968) the use of selfish genetic elements was proposed in 1994 by Hastings. The idea of using homing endonucleases to build self-replicating drives which are now realized with the help of the versatile molecular scissor CRISPR-Cas9 was already put forward in 2003 by Austin Burt (Burt 2003). Besides the spread of new traits with so called 'conversion drives', 'suppression drives' are aiming at a reduction or even a regional extinction of pest species or vectors of pathogens. Amongst other application fields suppression drives are envisaged for combating malaria by strongly reducing the number of some mosquito species which are the prime vectors for infectious diseases like malaria and dengue (Macias et al. 2017). Anticipated as a highly specific replacement for pesticides, GDs are considered to be applied against a number of invasive species that have become agricultural pests like the

B. Giese $(\varangle)$. J. L. Frieß

Institute of Safety/Security and Risk Sciences, University of Natural Resources

and Life Sciences, Vienna (BOKU), Austria

e-mail: bernd.giese@boku.ac.at

A. von Gleich

Department of Technological Design and Development, Faculty Production Engineering,

University of Bremen, Bremen, Germany

(C) The Author(s) 2020

A. von Gleich and W. Schröder (eds.), Gene Drives at Tipping Points,

https://doi.org/10.1007/978-3-030-38934-5_7 
cherry fruit fly Drosophila suzukii in California (Buchman et al. 2018) or rodents like mice or rats in New Zealand which pose a serious threat to agriculture and the native environment (Dearden et al. 2018). Even weeds have been proposed as targets for suppression drives (Neve 2018). Conversion drives are currently developed to render mosquitoes immune to pathogens or inhibit the penetration of ripening fruits by the cherry fruit fly due to a non-functional ovipositor (Regalado 2017).

A number of reasons for concern have been raised in the course of the discussion about GD development and their potential applications (Esvelt and Gemmell 2017; Ledford 2016; National Academies of Sciences 2016; Oye et al. 2014). They represent a potentially powerful genetic tool with unprecedented range in time and space. Current releases of GMOs are limited to a certain number of engineered organisms (mostly plants), a limited timeframe and a limited area with more or less established separation from wild relatives to prohibit vertical gene transfer to subsequent generations. With GDs a fast vertical gene transfer becomes the aim of the GMO-application. To ensure control of GDs or even strive for a kind of functional reversibility, a number of options have been proposed in recent years. A review of their potential, their reliability and their developmental stage is still missing. Furthermore, alternative approaches are excluded so far in a comparative evaluation. The present work should help to close this gap.

In addition to technical variations of GDs, which may yield an improved reliability or decrease their hazard and exposure potential as sources of possible risks, alternatives to GDs are as well included in the assessment which is given in this chapter. But the technology itself is only one factor in the generation of risks.

Additional exposure- and hazard potentials depend on the qualities and the vulnerability of the ecosystems into which the gene drives are introduced and on the specific aims and contexts of the gene drive application (e.g., agriculture, disease control or nature conservation) if the GD-system is not per se containing toxic or allergenic substances. Beyond these known adverse properties nearly any biochemical quality, e.g. an enzymatic feature, may turn out hazardous in a particular context. Thus, corresponding non-knowledge on the final behaviour hinders a characterization of the total hazard potential in very early innovation phases where results of experimental tests and specific application conditions are not available. Thus, as a precautionary approach especially in anticipation of environmental release, it is advisable to focus more on the exposure potential instead of the hazard potential. A high exposure strongly increases the possibility of unforeseen interactions in the environment, and thus increases the realm of ignorance about possible adverse effects. That is the lesson learned from the release of persistent synthetic chemicals into the environment (e.g. Chlorofluorocarbons [CFC] and Persistent Organic Pollutants [POPs]). To focus on exposure relevant qualities yields options on how to limit or even decrease the exposure potential emanating from GDs. It may thereby reduce the potential for unforeseen and unmanageable interactions of GDs in the environment. Reducing the exposure potential is thus a promising approach of risk reduction for GD.

The exposure potential of GDs is determined by qualities of the GD or the GDO that are related to (a) the spatial and (b) the temporal spread. These could be for example 
- stability of the GD against inactivation by mutations,

- impact of the GD on the fitness of the target species,

- frequency of inheritance

as GD-specific qualities. With regard to the target species the following qualities may have an influence:

- mobility,

- life expectancy,

- inheritance,

- number of offspring,

- probability of crossbreeding,

- frequency of releases and initial number of released individuals carrying the GD,

- regional distribution of the target population,

- interconnections between subpopulations.

In case of gene drives that are exclusively applied in laboratories, exposure to the environment is mainly determined by the containment of the experimental settings. We may call this an extrinsic containment. For an overview of extrinsic containment strategies see (Akbari et al. 2015; Benedict et al. 2008). If barriers are characteristic for extrinsic containment, ecological containment can be seen as a special form of this type of containment where spatial separation serves as a means for safety. Here, wild type populations of the target species or wild relatives are lacking in the geographic region where the GDOs are released or where the GD experiments are performed in a laboratory. Additionally, environmental conditions should not favour the settlement of these wild species. With regard to the safety of laboratory experiments with GDO, ecological containment is supported by environmental conditions that are not favourable for the respective GDO-species, e.g. regarding temperature. However, ecological containment is an option of limited reliability because GDOs might be transported intentionally or unintentionally along with other cargo in ships, cars or planes and some may as well survive unfavourable climate (Min et al. 2017b).

Additionally, laboratory safety can be improved by an appropriate intrinsic containment. ${ }^{1}$ That is GDs or specific target species are dependent on synthetic substances or limited in spread due to their specific technical organization. Because extrinsic containment is practically only an option for GDs applied in laboratories, in this chapter we will focus on approaches for intrinsic containment with relevance for GDO that are to be released into the environment.

\footnotetext{
${ }^{1}$ Cf. Wright et al. (2013, 1223): "Biology can achieve a lot in a contained environment; however, physical containment alone offers no guarantees. For example, no matter how ingenious a protective device or material may be for a GMM field application, an inventive way will eventually be found by an operator to compromise it. Failure in this case is a matter of when, not if. Although some form of physical containment is obviously prudent, inbuilt biological mechanisms remain crucial to biosafety."
} 


\section{Intrinsic Containment}

The intrinsic containment of a GDO is either due to the reproductive incompatibility of the target species with wild type strains and related species or caused by the specific character of the GD. For instance, in case of homing endonuclease-based GDs (HEG-drives) the latter may be due to a unique target sequence. Accordingly, Min et al. differentiate between reproductive and molecular confinement as variants of intrinsic containment (Min et al. 2017b, p. 55).

For GDOs used in the laboratory, a number of special options for intrinsic containment are available that have been already used as safety measures for experiments with GMOs. For applications in laboratory facilities it is advisable to use organisms that are not viable outside laboratory conditions. Containment strategies can make use of the following options:

- dependency on the supply of a synthetic substance which is only available in the laboratory, (see RIDL, Chap. 2),

- a kill switch which is activated when a certain food compound is lacking,

- reproductive containment using laboratory strains unable to produce viable offspring with wild conspecifics, e.g., the use of Drosophila with compound autosomes, where the left arms of two chromosomes are joint together in one chromosome and the right arms in another, making these specimen infertile with wild types (Akbari et al. 2015).

For GDO-species that are determined to be released into the environment, safety strategies become more challenging because it is intended that gene drives spread within a population by mating of GDOs with their wild conspecifics. Meanwhile a number of approaches to limit the spread of GDOs in time and space have been proposed (Esvelt et al. 2014; Noble et al. 2019). Within the following section potential options are presented.

\section{Safety Options for GDO-Releases}

Safety strategies for GD applications can be grouped into techniques that represent either gene drive modifications and other transgenic constructs respectively or rather alternative approaches which are based on naturally occurring mutations and parasitic infections that enable population control in a comparable way. Options for both types of approaches, either relying on genetic engineering or harnessing naturally occurring anomalies are presented in the following chapters. 


\section{Molecular Modifications of Gene Drives as Safety Strategy}

\section{Split Drive}

The idea of a split drive to limit the uncontrolled spread of a GD is based upon the separation of the genetic components of CRISPR/Cas based HEG-drives. To that end, the endonuclease gene and the genetic information of the single guide RNA (sgRNA) can be located at different loci in the genome of which only one of the genes is inherited as a GD. For example, if the sgRNA code for a target sequence resembles its own insertion site, only the inheritance of the sgRNA will be biased in a super-Mendelian fashion. Inheritance of the endonuclease gene is by contrast determined by Mendelian dynamics and should therefore lead to a loss of the Cas 9 gene and thus limit the spread of the sgRNA gene after a few generations as long as Cas9 does not provide a fitness gain (cf. DiCarlo et al. 2015).

Malfunction of a split drive can be caused by molecular recombination events of the genome that may move the Cas9-gene adjacent to the sgRNA sequence. If reading frames are intact the result would be a complete and therefore potentially autonomous GD consisting of the information for the endonuclease as well as a sgRNA. At least the non-intended integration of sgRNA-sequences has already been observed ( $\mathrm{Li}$ et al. 2016). Homology directed repair of the next sgRNA guided cleavage of a target site would then result in copying of sgRNA and endonuclease genes. However, the probability for such an event is low and it can be further reduced by a low homology between the locations of both elements of the split drive within the genome (Akbari et al. 2015). Additionally, developers of GD recommend to combine this strategy with a second form of containment (Akbari et al. 2015).

Besides a separation within the genome, other variants of split drives are imaginable. At least for some eukaryotic species, the genetic information of the endonuclease Cas 9 can be located episomally, outside the genome on an extrachromosomal plasmid. DiCarlo et al. experimentally verified the function of a split gene drive with episomal Cas9 gene in yeast (DiCarlo et al. 2015). But in addition to a verification of the gene drive-biased inheritance an assessment of the limiting effect of this kind of split drive system is still lacking. The bias of inheritance ceases with each generation as plasmids get lost. And even if the endonuclease gene is moved inside the genome by recombination which is a rare but not impossible event, this gene will most likely be inherited by Mendelian dynamics and therefore the "drive" of the sgRNA fades over the next generations.

An even more expanded version of a split drive would be a constellation with different strains carrying parts of the genetic information of a gene drive. For example, the gene for Cas9 can be part of the genome of a strain that mates with a sgRNAbearing strain. In such an approach the strain carrying Cas9 has to be released continuously to keep the drive running, because the Cas9-gene is only passed to offspring with a 50\% chance of inheritance if the sgRNA targets its own insertion sequence (Akbari et al. 2015). 


\section{Daisy Chain Drives}

In a daisy drive-system, a number of gene drives is dependent on each other in a linear (or circular) manner, in that each of the drives' sgRNAs is encoded for a target site which consists of the flanking elements of the next drive in the daisy chain. Therefore, no element of the chain drives itself. The single drives of a chain can even be located on different chromosomes. In a linear chain (of at least two elements), the first drive has no predecessor which would cut a target site in which the first drive could be integrated by homologous recombination. Therefore, it will be the first element of the daisy chain that gets lost by the means of natural selection. Accordingly, the other elements of the chain will successively get lost over time. In the daisy drive proposed by Noble et al. (2019), the last element of the chain carries the "payload" (the cargo gene). If finally the last sgRNA of the chain is lost, the top element will fade away as well, if it does not deliver any fitness gain (Noble et al. 2019). As for split drives, recombination may create an independent drive which then overcomes the limiting effect of the daisy chain.

In 2017, Min et al. proposed a "Daisy field" drive-system (Min et al. 2017b), where multiple sgRNAs are encoded separately from the locus harbouring CRISPR nuclease and a potential payload gene, but all sgRNAs share the same target sequence. Compared with a daisy chain drive, the daisy field system works with just a single cut-and-copy event and thus should be more reliable and less prone to non-intended recombination events that may create a global drive. According to Min et al. the fitness cost should be small, because the multiple elements of a daisy field drive (except for the cargo genes) consist of sgRNAs. Only for a number of initial generations, the genetic information for the nuclease and the payload is inherited to all offspring (by homologous recombination) due to the fact that with each generation the sgRNA daisy elements $\left(\mathrm{N}_{\mathrm{sgRNA}}\right)$ are inherited with only $50 \%$ chance. Because with every generation the average number of sgRNAs per organism is cut in half, the nuclease and cargo-genes will be inherited by the drive for roughly $\left(\mathrm{N}_{\mathrm{sgRNA}}+1\right)$ generations (Min et al. 2017b). According to this theory, the initial number of sgRNAs should therefore be a means to tune the spread of a drive. Daisy field drives can be combined with a daisy drive chain for instance as the first element of a drive chain (Min et al. 2017b).

In order to prevent the accidental generation of a global drive by recombination events that would move gRNA adjacent to the nuclease, sequences of gRNA and nuclease (including the cargo genes) should not have sequence homology. Min et al. suggest to have not more than 12 base pairs homology. Additionally, they recommend to place the nuclease more than $100 \mathrm{~kb}$ apart from gRNA repeat sequences (Min et al. 2018).

In a further prepublication, Min et al. propose the concept of "Daisy quorum" drives as an extension of a daisy drive-application by the subsequent release of wildtype organisms or a suppression drive targeting the previously altered population. This combination should lead to a low frequency of the engineered genes which then theoretically get lost over time by natural selection, if it does not provide a fitness gain for the organism expressing them (Min et al. 2017a). 


\section{Limitation by Secondary Releases}

Secondary releases of sexually compatible members of the target species have been mentioned quite early as a method to limit the spread of GDs and even as a means to reverse the functionality of the drive in the already affected individuals. The proposed approaches range from releases of sterile wild type individuals that should breed with the genetically altered organisms, thereby slowing down the spread of the drive (Montell cited in McFarling 2017), to the release of GDOs equipped with overwriting drives that target the initial drive sequence. Particularly tricky approaches for the removal of CRISPR/Cas9-drives should even function without a full GDfunctionality: They only rely on gRNAs whose target sequences are flanking the sequence of the previously released GD or are located within the coding sequence of Cas9. Due to the cellular presence of Cas9 from the released drive, which is now guided by the gRNA of the removal construct, excision or disruption of the GD and replacement with the coding cassette of the removal construct is enabled (cp. Zentner and Wade 2017).

Most probably, all these types of approaches for secondary releases are rather imperfect in their reliability as a means to limit or reverse the impact of released GDs because their spread must at least cover the spatial and numerical distribution of the initial drive. In particular, with regard to overwriting drives, a second (overwriting) drive has to reach every individual that was altered by the initial drive to exclude the possibility of recurrence-which cannot be excluded at least for very effective drives with a low threshold such as CRISPR/Cas-based systems. Furthermore, as long as the GD is not strictly threshold-dependent, a release of sterile wild types is probably only able to slow down the spread of the drive. However, overwriting drives have been discussed in the community of scientists engaged in GD-development and Esvelt, on his webpage, demands that an overwriting drive should be built in parallel to any new gene drive. ${ }^{2}$ According to Esvelt an overwriting — or "immunizing reversal" drive as he calls it - should not only target the individuals that are already altered by the initial drive: Besides overwriting the GD-code in the latter, it should render the wild type-population immune to further spread of the initial drive. He admits that "reversal" only refers to the phenotype, not the genotype of the altered organisms, because the second drive will not be able to restore the original genetic code. Traces of the genetic information of Cas9 and the sgRNA will remain in their genome.

\section{Limitation by Dependence}

Besides a specific genetic structure that may serve as a means to limit the spread of GDs, their ongoing super-Mendelian inheritance could be limited by different types of dependence. External factors that may have an impact on the dynamics of GD

\footnotetext{
${ }^{2} \mathrm{cf}$. https://www.sculptingevolution.org/genedrives/safeguards.
} 
distribution are environmental conditions, a specific (synthetic) target sequence or a (synthetic) inductor molecule.

In the latter case, the inductor is necessary to induce the expression of the endonuclease or the sgRNA (if a CRISPR/Cas-based GD is used). If the toxin in toxinantidote drives is constitutively repressed, an inductor would be necessary to release the toxin and thereby activate the drive. But this method may turn out as difficult to realize for multicellular eukaryotic organisms, because the inductor has to be present in the germline and therefore cross several barriers of the organism's body. As an opposite strategy to an inductor, a toxin might be used which only impacts GDOs due to a sensitivity mediated by the genomic manipulation or the cargo of the gene drive.

If a HEG-drive is engineered to target a specific sequence that is unique to a certain number of individuals, it can be used to limit the spread of the drive to subpopulations of a species or previously released GMOs. Esvelt and colleagues called the limitation to subpopulations a "precision drive" (cp. Esvelt and Gemmell 2017; Min et al. 2017b, p. 49). But according to Esvelt et al. it could be difficult to realize this drive type. First, to assure that the drive targets at least the subpopulation, it has to withstand the occurrence of resistant alleles. For that purpose, they suggest to have a multiplex drive with at least three target sites. Additionally, these sites have to be located within the sequence of essential genes. Moreover, for the application of CRISPR/Cas drives, these "natural" sequences have to contain a protospacer adjacent motif (PAM) to enable binding of the endonuclease to the target site.

These obstacles could be overcome if the GD targets only synthetic sequences encoded in genetically engineered organisms. As "synthetic site targeting" this safety approach was tested in yeast in an initial experiment (DiCarlo et al. 2015). A major advantage of this approach is the fact that depending on the sequence similarity with natural sequences the sgRNA of an HEG-drive must undergo several mutations before it may serve to place a drive in a natural sequence. For the application in isolated populations e.g., on islands, Min et al. suggested to use target sequences for HEG-drives that are recoded by an initial drive to provide an appropriately prepared population (Min et al. 2017b, p. 49).

The idea of Craig Montell is an example for a dependency on an environmental factor: He suggested to engineer mosquitoes with a self-destruction mechanism which is activated when an environmental parameter, e.g. temperature, reaches a threshold (Montell cited in McFarling 2017). In order to catch every gene drive mosquito by this technique, it has to be included in the cargo of the drive. Besides the necessary increase in size for the additional cargo information, the major drawback of this approach most probably lies in its vulnerability to mutations in the self-destruction mechanism. 


\section{Limitation by Genetic Instability}

Experimental tests of CRISPR/Cas-GDs revealed a significant restraining impact of resistance alleles in target populations. Selection of resistance to a CRISPR/CasGD was first documented by Hammond et al. in 2017. After an initial increase of GDO in caged mosquito populations over less than 10 generations they observed a gradual increase of the ratio of resistant alleles within the experimental time frame of 25 generations (Hammond et al. 2017). Resistant alleles may occur due to NonHomologous End Joining (NHEJ), Microhomology Mediated End Joining (MMEJ), by incomplete Homology Directed Repair (HDR) or may originate from sequence variations within the population (Champer et al. 2017). Within the sequence of essential genes of a species the probability is high that mutations compromise the viability of the organism. Thus target sites within essential genes that are highly conserved among the members of a species are likely to confer more stability with regard to the spread of the GD. As Kyrou et al. have shown, this strategy is successful in suppressing the selection of resistant alleles in Anopheles gambiae (Kyrou et al. 2018). An approach for GD-limitation — at least as an additional feature — could be established by a high probability for mutations due to only a single target site within a non-essential gene and only a single sgRNA locus.

\section{Alternative Approaches to Synthetic Gene Drives}

Population control can potentially be achieved with alternative approaches as well. Alternative approaches can be divided into options based on genetic engineering as the use of transgenes, mutations causing sterility and the application of naturally occurring effects with a dampening impact on population growth. Important examples of both groups are presented within the next two chapters.

\section{Release of Insects Carrying a Dominant Lethal Allele (RIDL) as an Alternative Genetic Engineering Approach}

For the RIDL-approach laboratory-reared organisms equipped with a dominant lethal gene are mass released to reduce the number of offspring in a wild population (Thomas et al. 2000). The dominant lethal gene prohibiting development of the offspring is cloned into the insects. Offspring dies at zygotic, larval or pupal stage. There are two varieties of RIDL. In the bi-sex RIDL approach, the offspring of both sexes die in premature stages (Harris et al. 2011; Phuc et al. 2007). In the female specific RIDL approach (fsRIDL), only female offspring die (Schliekelman and Gould 2000; Thomas et al. 2000). Heterozygous sons then pass the lethal gene to half of both sexes of their offspring, of which the inheriting females will die. Female specific RIDL 
strains have been developed for Aedes aegypti and Aedes albopictus, using flightlessness as a lethal trait (Alphey et al. 2013). Since only genetically engineered males are released, the bi-sex RIDL approach is considered self-limiting, while fsRIDL has to be considered self-sustaining, albeit for a limited number of generations.

RIDL organisms are furthermore equipped with a fluorescent marker for distinction from wild type animals and a bistable switch, a tetracycline-repressible transcription activator (tTAV) which binds to the promotor of the lethal gene. In the presence of tetracycline, which is included in the laboratory organisms' diet, the transcription activator is repressed, allowing for normal procreation (Thomas et al. 2000).

However, apart from the observation that the lethality of RIDL-offspring fails in $3 \%$ of cases there is evidence that due to "naturally occurring" contamination of food with tetracycline, RIDL-offspring become viable and survive (RodriguezBeltran 2012). Another drawback with regard to the safety of this approach is that mechanical sex sorting fails in $0.33 \%$ of cases (Lacroix et al. 2012).

In caged trials it was shown that RIDL mosquitoes have an estimated competitiveness to wild type males of 0.56 (Harris et al. 2011). Male RIDL-olive flies are outcompeted for mating in cages, with $46 \%$ of females mating RIDL-flies (Ant et al. 2012). Thus, to continually suppress a population, a high number of periodical releases with large numbers of insects is required. Field trials with mosquitoes were carried out in the Cayman Islands, Malaysia, Brazil, and Panama (Alphey 2014; Gorman et al. 2015; Subbaraman 2011).

\section{Resistance by Transgenes}

Different approaches have been published so far for the suppression of mosquito populations e.g., by the expression of antibodies against the malaria parasite or RNAi-expression to suppress arbovirus replication, but expression of transgenes may represent a fitness cost and therefore might get lost before significant results in population control are achieved, moreover resistance of pathogens may evolve over time (Alphey et al. 2013).

\section{Population Control by Mutagenesis: The Sterile Insect Technique (SIT)}

SIT is applied for population suppression of disease transmitting mosquitoes or pest insects like the Mediterranean fruit fly since the middle of the 20th century (Dyck et al. 2005). The technical approach of SIT consists in the release of masses of sterile insects. Sterile males are the preferred candidates for release because release of both sexes (a) seems to weaken the suppressing effect due to mating between the sterilized males and females and (b) in case of mosquito control a release of females would increase the potential of biting humans. Mating of the released males with wild females leads to a decline of the target population and in extreme cases to its collapse. SIT-insects are sterilized by radiation or chemicals. The induction 
of dominant lethal mutations in the treated sperm leads to death of the majority of eggs that are fertilized by this sperm. For SIT it is important that sterile males are not agametic. Spermatozoa still have to be produced to keep up sperm competition with sperm from fertile males in remating females (Alphey et al. 2013).

\section{Harnessing Naturally Occurring Phenomena for Population Control}

\section{The Trojan-Female-Technique (TFT)}

For some species male fertility seems to depend on mutations in mitochondrial DNA. These male-specific deleterious mutations escape selection processes in the female germline, because mtDNA is maternally inherited (Beekman et al. 2014; Frank and Hurst 1996 cited in Wolff et al. 2017). Their application may yield a long lasting approach for population control across several generations. A corresponding approach is called Trojan Female Technique (Gemmell et al. 2013). By using TFT for population control, genome editing can be avoided if female insects with mtDNA-mutations are selected that are highly effective with regard to male infertility. Therefore, neither transgenic nor genome edited organisms are necessary for a TFT-approach and legal preparation of application would be clearly simplified.

mtDNA-mutations causing sub- or complete infertility have been reported for Drosophila, seed beetles, hares and humans (cf. Wolff et al. 2017). A first proof of concept in fruit flies was shown by Wolff et al. (2017). They used a mitochondrial haplotype from a population of $D$. melanogaster that leads to complete male sterility in combination with a particular genomic background in the nucleus. The suppressive effect persisted over 10 generations in a density controlled population were egg numbers in each generation are carefully regulated. Over the course of the experiment (10 generations) no mutations in the nuclear genome could be detected that compensated for mutations in the mitochondrial DNA which caused the male infertility. Additionally, no reduction in frequency of the TFT-haplotype was detected. This observation highlights the power of the TFT approach as it may be sufficient to apply it in a single release and achieve a suppression over multiple generations. However, the effect was smaller than expected and unfortunately for more natural conditions without density control (stochastic contractions and expansions in population size are possible) no significant effect could be detected (Wolff et al. 2017).

\section{Wolbachia Parasites and Cytoplasmic Incompatibility}

In 1967 it was first described that the bacterial endosymbiont Wolbachia pipientis is able to bias inheritance of infected mosquitoes leading to the spread of the bacteria in populations of the host (cf. Macias et al. 2017, p. 4). Due to its cytoplasmic localization Rickettsia bacteria of the genus Wolbachia are maternally passed on to their offspring and infect $\sim 52 \%$ of the terrestrial arthropod species (Weinert et al. 2015, p. 3). As determined in Drosophila and Aedes aegyti, infection with Wolbachia 
bacteria may reduce the host life span by roughly half (Lin et al. 2012). Furthermore, Wolbachia poses effects such as male killing, feminization, parthenogenesis and cytoplasmic incompatibility (Burt 2014). In terms of population control or measures against infectious diseases two approaches are possible with Wolbachia:

1. An infection of mosquitoes with certain strains of Wolbachia can be used to reduce susceptibility of the insects to a range of different pathogens (Alphey 2014; Alphey et al. 2013; Carrington et al. 2018). The Wolbachia strain w Mel for example blocks the development of dengue in Ae. aegypti.

2. If male mosquitoes are infected with specific Wolbachia strains, mating with uninfected females or females infected with different Wolbachia strains is unsuccessful due to a cytoplasmic incompatibility of eggs and sperm (wild female mosquitoes are usually infected with other Wolbachia strains) (Blagrove et al. 2012; Burt 2014).

The latter corresponds to a population suppression approach and is called "incompatible insect technique (IIT)" (Burt 2014). Infected females will always produce infected offspring. The application is complicated because for IIT with infected males the release of only male carriers is absolutely essential as a single female carrier could potentially drive the alien Wolbachia strain into the wild population, mitigating the desired effect. The latter effect would be desired in an invasive application, which is potentially self-sustaining. In another invasive application, organisms infected with two different Wolbachia strains, each incompatible with the other, are released. This is the so called bidirectional approach. The result would be the formation of three different subpopulations, wild type, Wolbachia strain A and Wolbachia strain B.

The use of Wolbachia bacteria for population and disease control may come along with a number of drawbacks. As reported in Alphey et al. (2013) infection with Wolbachia could cause a selection towards viruses with higher titre in humanbiting mosquitoes (Alphey et al. 2013). Furthermore, due to the need for human blood to produce viable eggs, wMel-infected mosquitoes may develop an increased preference to bite humans (Alphey et al. 2013). Evolutionary changes might affect the relationship between the parasite and its host: Resistance of mosquitoes against viruses like dengue as a result of their immune response against Wolbachia might be dampened due to a co-evolution of the mosquito and the Wolbachia parasite and even the virus may adapt over time (Macias et al. 2017, p. 13). For Wolbachia-based approaches experience was gained by a number of field trials in recent years (see Table 7.1).

\section{Overview of Potential Safety Mechanisms}

The different strategies presented here that may help to overcome the potential risks of GD vary remarkably in that they on the one hand rely on genetic engineeringpartially even consist in GD-variants-and on the other hand they represent real alternatives which are not based on genetic engineering at all. The sheer variety 
Table 7.1 Known Wolbachia field trials (updated collection of Alphey 2014)

\begin{tabular}{l|l|l|l}
\hline Date & Location & Method & Outcome \\
\hline 2010 & French Polynesia & IIT & $\begin{array}{l}\text { Sustained release of Aedes } \\
\text { polynesiensis males infected with a } \\
\text { Wolbachia strain from Aedes } \\
\text { riversi induced sterility in a target } \\
\text { population }\end{array}$ \\
\hline $2011-$ Present & Australia & Invasive Wolbachia & $\begin{array}{l}\text { Release of infected male and } \\
\text { female Aedes aegypti led to the } \\
\text { invasion and establishment of } \\
\text { different Wolbachia strains; } \\
\text { releases in multiple additional } \\
\text { areas are in progress }\end{array}$ \\
\hline $2013-2018$ & Vietnam & Invasive Wolbachia & $\begin{array}{l}\text { Release of wMelPop-infected male } \\
\text { and female Aedes aegypti on an } \\
\text { island }\end{array}$ \\
\hline 2017 & California & IIT & $\begin{array}{l}\text { Release of male } \\
\text { Wolbachia-infected Aedes aegypti } \\
\text { to suppress the natural population } \\
\text { in Fresno County }\end{array}$ \\
\hline
\end{tabular}

shows that at least theoretically there are options for population control besides the application of GDs. Nonetheless, these approaches differ strongly in their qualities with regard to the aim of reducing exposure to GD and minimizing potential hazards associated with their release. And besides the fact that the effectivity of most of these options is not yet experimentally verified, they are connected to different vulnerabilities that may preclude particular applications. To facilitate an overview on the approaches presented in this chapter, the basic strategy, their aim with regard to hazard and exposure of GD, major vulnerabilities as well as a rough characterization of their developmental stage are given in Table 7.2.

\section{Summary}

As the list in Table 7.2 shows, design options for HEG-GDs discussed so far are aiming at a reduction of environmental exposure. Additionally, the hazard potential of GDs will most probably be very case-specific because it is largely dependent on the genomic localization of the drive and the function of possible cargo genes. Hence, a focus on exposure minimization is justified. Potentials of exposure and hazards connected with the use of transgenes for genomic modifications can be reduced by alternative approaches based on naturally occurring phenomena with impact on the population size. All design variants of HEG-GDs with reduced risk potential are rather poorly characterized so far. Proofs of principle in a scale that enables reliable statements on their performance with regard to releases are lacking. In any case, 
Table 7.2 Overview of (a) design options for HEG-GDs that may decrease their risk potential and (b) alternative approaches for population control

\begin{tabular}{|c|c|c|c|c|}
\hline Technique & Main strategy & $\begin{array}{l}\text { Aim } \\
\text { (Hazard/Exposure) }\end{array}$ & Vulnerability & $\begin{array}{l}\text { Remarks/ } \\
\text { developmental } \\
\text { stage }\end{array}$ \\
\hline \multicolumn{5}{|c|}{ HEG-GD design options } \\
\hline Split drive & $\begin{array}{l}\text { Separation of } \\
\text { genes for } \\
\text { sgRNA and } \\
\text { endonuclease }\end{array}$ & $\begin{array}{l}\text { Limitation of } \\
\text { exposure to GDO } \\
\text { (temporal and spatial) }\end{array}$ & $\begin{array}{l}\text { Co-localization of genes } \\
\text { for Cas9 and sgRNA by } \\
\text { recombination resulting } \\
\text { in a global drive }\end{array}$ & $\begin{array}{l}\text { Tested in yeast } \\
\text { but no } \\
\text { experimental } \\
\text { proof for the } \\
\text { limiting potential } \\
\text { so far }\end{array}$ \\
\hline $\begin{array}{l}\text { Daisy chain } \\
\text { drive/ Daisy } \\
\text { field drive }\end{array}$ & $\begin{array}{l}\text { Chain of } \\
\text { interdependent } \\
\text { drives/multiple } \\
\text { separately } \\
\text { encoded } \\
\text { sgRNAs for } \\
\text { endonuclease } \\
\text { (and cargo) } \\
\text { target sequence }\end{array}$ & $\begin{array}{l}\text { Limitation of } \\
\text { exposure to GDO } \\
\text { (temporal and spatial) }\end{array}$ & $\begin{array}{l}\text { Co-localization of } \\
\text { genes for Cas } 9 \text { and } \\
\text { sgRNA targeting its } \\
\text { own insertion site by } \\
\text { recombination resulting } \\
\text { in a global drive }\end{array}$ & $\begin{array}{l}\text { No experimental } \\
\text { proof for the } \\
\text { limiting potential } \\
\text { so far }\end{array}$ \\
\hline $\begin{array}{l}\text { (Synthetic) } \\
\text { inductor } \\
\text { molecule }\end{array}$ & $\begin{array}{l}\text { Dependency on } \\
\text { the supply of a } \\
\text { substance }\end{array}$ & $\begin{array}{l}\text { Limitation of } \\
\text { exposure to GDO by } \\
\text { GD deactivation }\end{array}$ & $\begin{array}{l}\text { Germline in } \\
\text { multicellular organisms } \\
\text { might be difficult to } \\
\text { target with an inductor }\end{array}$ & $\begin{array}{l}\text { No exact } \\
\text { theoretical } \\
\text { description and } \\
\text { no experimental } \\
\text { proof for the } \\
\text { deactivating } \\
\text { potential so far }\end{array}$ \\
\hline $\begin{array}{l}\text { Specific } \\
\text { (synthetic) } \\
\text { target } \\
\text { sequence }\end{array}$ & $\begin{array}{l}\text { Targeting of a } \\
\text { unique target } \\
\text { sequence }\end{array}$ & $\begin{array}{l}\text { Exposure limitation } \\
\text { to GDO by targeting a } \\
\text { genetic subpopulation }\end{array}$ & $\begin{array}{l}\text { Similarity to sequences } \\
\text { in the general } \\
\text { population }\end{array}$ & $\begin{array}{l}\text { "Synthetic site } \\
\text { targeting" tested } \\
\text { in yeast in } \\
\text { laboratory scale }\end{array}$ \\
\hline $\begin{array}{l}\text { Environmental } \\
\text { conditions }\end{array}$ & $\begin{array}{l}\text { Self-destruction } \\
\text { depending on } \\
\text { environmental } \\
\text { conditions }\end{array}$ & $\begin{array}{l}\text { Limitation of } \\
\text { exposure to GDO }\end{array}$ & $\begin{array}{l}\text { Mutations deactivating } \\
\text { the self-destruction } \\
\text { system }\end{array}$ & $\begin{array}{l}\text { No exact } \\
\text { theoretical } \\
\text { description and } \\
\text { no experimental } \\
\text { proof for the } \\
\text { deactivating } \\
\text { potential so far }\end{array}$ \\
\hline $\begin{array}{l}\text { Genetic } \\
\text { instability }\end{array}$ & $\begin{array}{l}\text { Accumulation } \\
\text { of GD-resistant } \\
\text { target } \\
\text { sequences due } \\
\text { to mutation and } \\
\text { sequence } \\
\text { variations }\end{array}$ & $\begin{array}{l}\text { Limitation of } \\
\text { exposure to GDO, } \\
\text { slowdown of GD } \\
\text { spread }\end{array}$ & $\begin{array}{l}\text { Incomplete reduction of } \\
\text { the GD frequency }\end{array}$ & $\begin{array}{l}\text { First experimental } \\
\text { observations in } \\
\text { laboratory scale }\end{array}$ \\
\hline \multicolumn{5}{|c|}{ Secondary release } \\
\hline $\begin{array}{l}\text { Overwriting } \\
\text { drive }\end{array}$ & $\begin{array}{l}\text { Release of } \\
\text { secondary GD } \\
\text { targeting the } \\
\text { sequence of the } \\
\text { first drive }\end{array}$ & $\begin{array}{l}\text { Reducing exposure to } \\
\text { GDO by } \\
\text { deactivation/limitation } \\
\text { of the initial drive and } \\
\text { immunization of the } \\
\text { target population }\end{array}$ & $\begin{array}{l}\text { Dependence on perfect } \\
\text { coverage of the first } \\
\text { drive's distribution, } \\
\text { sensitive to mutations }\end{array}$ & $\begin{array}{l}\text { No experimental } \\
\text { proof for the } \\
\text { limiting potential } \\
\text { so far }\end{array}$ \\
\hline
\end{tabular}


Table 7.2 (continued)

\begin{tabular}{|c|c|c|c|c|}
\hline Technique & Main strategy & $\begin{array}{l}\text { Aim } \\
\text { (Hazard/Exposure) }\end{array}$ & Vulnerability & $\begin{array}{l}\text { Remarks/ } \\
\text { developmental } \\
\text { stage }\end{array}$ \\
\hline $\begin{array}{l}\text { gRNA } \\
\text { targeting a } \\
\text { drive }\end{array}$ & $\begin{array}{l}\text { Release of } \\
\text { organisms } \\
\text { carrying gRNA } \\
\text { against the } \\
\text { sequence of the } \\
\text { released GD }\end{array}$ & $\begin{array}{l}\text { Reducing exposure to } \\
\text { GDO by deactivation/ } \\
\text { limitation of the initial } \\
\text { drive and } \\
\text { immunization of the } \\
\text { target population }\end{array}$ & $\begin{array}{l}\text { Dependence on perfect } \\
\text { coverage of the first } \\
\text { drive's distribution, } \\
\text { sensitive to mutations }\end{array}$ & $\begin{array}{l}\text { First experimental } \\
\text { proof-of-principle } \\
\text { in laboratory } \\
\text { scale in } \\
\text { Drosophila }\end{array}$ \\
\hline $\begin{array}{l}\text { Limitation by } \\
\text { sterility }\end{array}$ & $\begin{array}{l}\text { Release of } \\
\text { sexually } \\
\text { compatible but } \\
\text { sterile } \\
\text { organisms }\end{array}$ & $\begin{array}{l}\text { Slowdown up to } \\
\text { limitation of GD } \\
\text { spread (in case of high } \\
\text { threshold-drives) }\end{array}$ & $\begin{array}{l}\text { Dependence on perfect } \\
\text { coverage of the first } \\
\text { drive's } \\
\text { distribution/spread of } \\
\text { GD is only retarded }\end{array}$ & $\begin{array}{l}\text { No experimental } \\
\text { proof for the } \\
\text { limiting potential } \\
\text { so far }\end{array}$ \\
\hline \multicolumn{5}{|c|}{ Non-GD genetic modifications } \\
\hline RIDL & $\begin{array}{l}\text { Death of } \\
\text { offspring due to } \\
\text { dominant lethal } \\
\text { gene }\end{array}$ & $\begin{array}{l}\text { Limitation of } \\
\text { exposure due to } \\
\text { self-limiting } \\
\text { approach }\end{array}$ & $\begin{array}{l}\text { Mass releases of GMO } \\
\text { required, } \\
\text { tetracycline-dependence }\end{array}$ & $\begin{array}{l}\text { Successfully } \\
\text { applied in field } \\
\text { trials }\end{array}$ \\
\hline $\begin{array}{l}\text { Resistance by } \\
\text { transgenes }\end{array}$ & $\begin{array}{l}\text { Modification of } \\
\text { target } \\
\text { organisms } \\
\text { instead of } \\
\text { suppression }\end{array}$ & $\begin{array}{l}\text { Limitation of } \\
\text { exposure due to } \\
\text { Mendelian inheritance } \\
\text { pattern }\end{array}$ & Evolution of resistance & $\begin{array}{l}\text { First laboratory } \\
\text { experiments } \\
\text { showed transient } \\
\text { effects }\end{array}$ \\
\hline $\begin{array}{l}\text { Sterile insect } \\
\text { technique } \\
\text { (SIT) }\end{array}$ & $\begin{array}{l}\text { Mass release of } \\
\text { sterile insects }\end{array}$ & $\begin{array}{l}\text { Avoidance of hazard } \\
\text { and exposure of/to } \\
\text { GDO }\end{array}$ & $\begin{array}{l}\text { Periodic mass releases } \\
\text { required }\end{array}$ & $\begin{array}{l}\text { Long experience } \\
\text { in SIT } \\
\text { applications } \\
\text { (releases) }\end{array}$ \\
\hline \multicolumn{5}{|c|}{ Use of naturally occurring phenomena } \\
\hline $\begin{array}{l}\text { Trojan female } \\
\text { technique } \\
\text { (TFT) }\end{array}$ & $\begin{array}{l}\text { Harnessing } \\
\text { naturally } \\
\text { occurring } \\
\text { male-specific } \\
\text { mutations } \\
\text { causing } \\
\text { infertility }\end{array}$ & $\begin{array}{l}\text { Avoidance of hazard } \\
\text { and exposure of/to } \\
\text { GDO/GMO }\end{array}$ & $\begin{array}{l}\text { Up to now comparably } \\
\text { small effectivity }\end{array}$ & $\begin{array}{l}\text { First laboratory } \\
\text { experiments }\end{array}$ \\
\hline Wolbachia & $\begin{array}{l}\text { Suppression of } \\
\text { mosquito } \\
\text { populations or } \\
\text { reduction of } \\
\text { susceptibility of } \\
\text { mosquitoes to } \\
\text { pathogens }\end{array}$ & $\begin{array}{l}\text { Avoidance of hazard } \\
\text { and exposure of/to } \\
\text { GDO/GMO }\end{array}$ & $\begin{array}{l}\text { Possibly increased } \\
\text { virulence of pathogens } \\
\text { due to selection and } \\
\text { co-evolution }\end{array}$ & $\begin{array}{l}\text { First releases } \\
\text { already conducted }\end{array}$ \\
\hline
\end{tabular}

they will be difficult to achieve because with an experimental release the risk of uncontrolled spread in the case of malfunction is high.

Secondary releases of overwriting drives, gRNA targeting the sequence of a released drive or the release of sterile mating partners must be competent enough to cover all parts of a population that have been infected with the primarily released drive. It is therefore necessary to assure that mutations or a fitness burden do not 
interfere and reduce the intended effect of these countermeasures. A first proofof-principle in the laboratory scale was already published in 2016 for the secondary release of a gRNA-based system as a so-called Cas9-triggered chain ablation (CATCHA) (Wu et al. 2016). However, a demonstration of the effectiveness of options for secondary releases under more realistic conditions is still pending.

Genetic modification by RIDL and in particular SIT as non-GD techniques is far better characterized, but accompanied with high efforts for the mass releases that are necessary for both. The selective application of naturally occurring phenomena with influence on population size may represent the methods of choice if transgene spread should be avoided. Moreover, approval for application will probably be much easier to obtain than for techniques based on genetic engineering. For the use of Wolbachia results from some first experimental releases are already available. Successful smallscale field trials have motivated larger scale releases (Burt 2014). Unfortunately, for TFT, a theoretically quite promising approach, only some first experimental results in the laboratory scale are available. From these so far rather inconclusive data, no statement can be made with regard to the potential of this advantageous technique that does not depend on transgenes or infection with parasitic bacteria. Further research is needed to characterize the suitability of using TFT as an alternative approach for population suppression.

As this comparative overview shows, alternative approaches for GDs are limited to an application for population suppression. Only an infection with Wolbachia bacteria can also be used to reduce the susceptibility of the host organism to pathogens and thus change the properties of a population. So far, approaches based on Wolbachia as "cytoplasmic drive" (Dobson et al. 2002) instead of a genetic drive represent the most advanced and functional alternative to GDs. However, regardless of the natural origin of this approach, potential impacts have to be carefully investigated. It may turn out as a highly powerful method for population suppression whose control in spread (at least for the invasive approaches) is severely limited. Moreover, a spread of Wolbachia to non-target species is possible. Whether TFT is able to serve as a more controllable technique in this regard is worth further investigation.

\section{References}

Akbari, O. S., Bellen, H. J., Bier, E., Bullock, S. L., Burt, A., Church, G. M., et al. (2015). Safeguarding gene drive experiments in the laboratory. Science, 349, 927-929. https://doi.org/10. 1126/science.aac7932.

Alphey, L. (2014). Genetic control of mosquitoes. Annual Review of Entomology, 59, 205-224. https://doi.org/10.1146/annurev-ento-011613-162002.

Alphey, L., McKemey, A., Nimmo, D., Neira Oviedo, M., Lacroix, R., Matzen, K., et al. (2013). Genetic control of Aedes mosquitoes. Pathogens and Global Health, 107, 170-179. https://doi. org/10.1179/2047773213Y.0000000095.

Ant, T., Koukidou, M., Rempoulakis, P., Gong, H.-F., Economopoulos, A., Vontas, J., et al. (2012). Control of the olive fruit fly using genetics-enhanced sterile insect technique. BMC Biology, 10, 51. https://doi.org/10.1186/1741-7007-10-51. 
Beekman, M., Dowling, D. K., \& Aanen, D. K. (2014). The costs of being male: Are there sexspecific effects of uniparental mitochondrial inheritance? Philosophical Transactions of the Royal Society B, 369, 20130440. https://doi.org/10.1098/rstb.2013.0440.

Benedict, M., D’Abbs, P., Dobson, S. L., Gottlieb, M., Harrington, L. B., Higgs, S., et al. (2008). Guidance for contained field trials of vector mosquitoes engineered to contain a gene drive system: Recommendations of a scientific working group. Vector Borne Zoonotic Diseases, 8, 127-166. https://doi.org/10.1089/vbz.2007.0273.

Blagrove, M. S. C., Arias-Goeta, C., Failloux, A.-B., \& Sinkins, S. P. (2012). Wolbachia strain wMel induces cytoplasmic incompatibility and blocks dengue transmission in Aedes albopictus. Proceedings of the National Academy of Sciences of the United States of America, 109, 255. https://doi.org/10.1073/pnas.1112021108.

Buchman, A., Marshall, J. M., Ostrovski, D., Yang, T., \& Akbari, O. S. (2018). Synthetically engineered Medea gene drive system in the worldwide crop pest Drosophila suzukii. Proceedings of the National Academy of Sciences, 201713139. https://doi.org/10.1073/pnas.1713139115.

Burt, A. (2003). Site-specific selfish genes as tools for the control and genetic engineering of natural populations. Proceedings of Biology Sciences, 270, 921-928. https://doi.org/10.1098/rspb.2002. 2319.

Burt, A. (2014). Heritable strategies for controlling insect vectors of disease. Philosophical Transactions of the Royal Society B: Biological Sciences, 369, 20130432. https://doi.org/10.1098/rstb. 2013.0432 .

Carrington, L. B., Nguyen Tran, B. C., Hoang Le, N. T., Hue Luong, T. T., Thanh Nguyen, T., Thanh Nguyen, P., et al. (2018). Field- and clinically derived estimates of Wolbachia-mediated blocking of dengue virus transmission potential in Aedes aegypti mosquitoes. PNAS, 115, 361-366. https:// doi.org/10.1073/pnas.1715788115.

Champer, J., Reeves, R., Oh, S. Y., Liu, C., Liu, J., Clark, A. G., et al. (2017). Novel CRISPR/Cas9 gene drive constructs reveal insights into mechanisms of resistance allele formation and drive efficiency in genetically diverse populations. PLOS Genetics, 13, e1006796. https://doi.org/10. 1371/journal.pgen.1006796.

Curtis, C. F. (1968). Possible use of translocations to fix desirable genes in insect pest populations. Nature, 218, 368-369.

Dearden, P. K., Gemmell, N. J., Mercier, O. R., Lester, P. J., Scott, M. J., Newcomb, R. D., et al. (2018). The potential for the use of gene drives for pest control in New Zealand: A perspective. Journal of the Royal Society of New Zealand, 48, 225-244. https://doi.org/10.1080/03036758. 2017.138503.

DiCarlo, J. E., Chavez, A., Dietz, S. L., Esvelt, K. M., \& Church, G. M. (2015). Safeguarding CRISPR-Cas9 gene drives in yeast. Nature Biotechnology, 33, 1250-1255. https://doi.org/10. 1038/nbt.3412.

Dobson, S. L., Marsland, E. J., \& Rattanadechakul, W. (2002). Mutualistic Wolbachia infection in Aedes albopictus: Accelerating cytoplasmic drive. Genetics, 160, 1087-1094.

Dyck, V. A., Hendrichs, J., \& Robinson, A. S. (Eds.). (2005). Sterile insect technique: Principles and practice in area-wide integrated pest management. Netherlands: Springer.

Esvelt, K. M., \& Gemmell, N. J. (2017). Conservation demands safe gene drive. PLOS Biology, 15, e2003850.

Esvelt, K. M., Smidler, A. L., Catteruccia, F., \& Church, G. M. (2014). Concerning RNA-guided gene drives for the alteration of wild populations. eLife, 3. https://doi.org/10.7554/eLife.03401.

Frank, S. A., \& Hurst, L. D. (1996). Mitochondria and male disease. Nature, 383, 224. https://doi. org/10.1038/383224a0.

Gemmell, N. J., Jalilzadeh, A., Didham, R. K., Soboleva, T., \& Tompkins, D. M. (2013). The Trojan female technique: A novel, effective and humane approach for pest population control. Proceedings of the Royal Society B, 280, 20132549. https://doi.org/10.1098/rspb.2013.2549.

Gorman, K., Young, J., Pineda, L., Márquez, R., Sosa, N., Bernal, D., et al. (2015). Short-term suppression of Aedes aegypti using genetic control does not facilitate Aedes albopictus. Pest Management Science, 72, 618-628. https://doi.org/10.1002/ps.4151. 
Hammond, A. M., Kyrou, K., Bruttini, M., North, A., Galizi, R., Karlsson, X., et al. (2017). The creation and selection of mutations resistant to a gene drive over multiple generations in the malaria mosquito. PLoS Genetics, 13, e1007039. https://doi.org/10.1371/journal.pgen.1007039.

Harris, A. F., Nimmo, D., McKemey, A. R., Kelly, N., Scaife, S., Donnelly, C. A., et al. (2011). Field performance of engineered male mosquitoes. Nature Biotechnology, 29, 1034-1039. https://doi. org/10.1038/nbt.2019.

Kyrou, K., Hammond, A. M., Galizi, R., Kranjc, N., Burt, A., Beaghton, A. K., et al. (2018). A CRISPR-Cas9 gene drive targeting doublesex causes complete population suppression in caged Anopheles gambiae mosquitoes. Nature Biotechnology, 36, 1062-1066. https://dx.doi.org/10. 1038/nbt.4245..

Lacroix, R., McKemey, A. R., Raduan, N., Wee, L. K., Ming, W. H., Ney, T. G., et al. (2012). Open field release of genetically engineered sterile male Aedes aegypti in Malaysia. PLOS ONE, 7, e42771. https://doi.org/10.1371/journal.pone.0042771.

Ledford, H. (2016). Fast-spreading genetic mutations pose ecological risk. Nature News. https:// doi.org/10.1038/nature.2016.20053.

Li, Z., Liu, Z.-B., Xing, A., Moon, B. P., Koellhoffer, J. P., Huang, L., et al. (2016). Cas9-guide RNA directed genome editing in soybean. Plant Physiology, 169, 960-970. https://doi.org/10. 1104/pp.15.00783.

Lin, Y.-C., Wu, J.-W., \& Liu, D.-P. (2012). New vector control measures on dengue fever: A literature review. Taiwan Epidemiology Bulletin, 28, 224-232.

Macias, V. M., Ohm, J. R., \& Rasgon, J. L. (2017). Gene drive for mosquito control: Where did it come from and where are we headed? International Journal of Environmental Research and Public Health, 14, 1006. https://doi.org/10.3390/ijerph14091006.

McFarling, U. L. (2017). Could this zoo of mutant mosquitoes lead the way to eradicating Zika? STAT News. https://www.statnews.com/2017/12/13/gene-drive-mosquitoes-darpa/.

Min, J., Noble, C., Najjar, D., \& Esvelt, K. M. (2017a). Daisy quorum drives for the genetic restoration of wild populations. BioRxiv. https://dx.doi.org/10.1101/115618

Min, J., Noble, C., Najjar, D., Esvelt, K. M. (2017b). Daisyfield gene drive systems harness repeated genomic elements as a generational clock to limit spread. bioRxiv preprint first posted online Feb. 6, 2017. https://dx.doi.org/10.1101/104877

Min, J., Smidler, A. L., Najar, D., \& Esvelt, K. M. (2018). Harnessing gene drive. Journal of Responsible Innovation, 5, S40-S65. https://doi.org/10.1080/23299460.2017.1415586.

National Academies of Sciences. (2016). Gene drives on the horizon: Advancing science, navigating uncertainty, and aligning research with public values. Washington, DC: The National Academies Press. https://doi.org/10.17226/23405.

Neve, P. (2018). Gene drive systems: Do they have a place in agricultural weed management? Pest Management Science, 74, 2671-2679. https://doi.org/10.1002/ps.5137.

Noble, C., Min, J., Olejarz, J., Buchthal, J., Chavez, A., Smidler, A. L., et al. (2019). Daisy-chain gene drives for the alteration of local populations. Proceedings of the National Academy of Sciences 1-8. https://doi.org/10.1073/pnas.1716358116.

Oye, K. A., Esvelt, K., Appleton, E., Catteruccia, F., Church, G., Kuiken, T., et al. (2014). Regulating gene drives. Science, 345, 626-628. https://doi.org/10.1126/science.1254287.

Phuc, H. K., Andreasen, M. H., Burton, R. S., Vass, C., Epton, M. J., Pape, G., et al. (2007). Lateacting dominant lethal genetic systems and mosquito control. BMC Biology, 5, 1-11. https://doi. org/10.1186/1741-7007-5-11.

Regalado, A. (2017). Farmers seek to deploy powerful gene drive. MIT Technology Review Accessed 12.13.17.

Rodriguez-Beltran, C. (2012). GM mosquitoes: Survival in the presence of tetracycline contamination. TWN Biosafety Briefing, 16.02.12, https://www.biosafety-info.net/article.php?aid=878. Accessed 09.08.17.

Schliekelman, P., \& Gould, F. (2000). Pest control by the release of insects carrying a female-killing allele on multiple loci. Journal of Economic Entomology, 93, 1566-1579. 
Simon, S., Otto, M., Engelhard, M. (2018). Synthetic gene drive: between continuity and novelty. EMBO Rep. e45760. https://doi.org/10.15252/embr.201845760.

Subbaraman, N. (2011). Science snipes at oxitec transgenic-mosquito trial. Nature Biotechnology, 29, 9-11.

Thomas, D. D., Donnelly, C. A., Wood, R. J., \& Alphey, L. S. (2000). Insect population control using a dominant, repressible. Lethal Genetic System Science, 287, 2474. https://doi.org/10.1126/ science.287.5462.2474.

Weinert, L. B., Araujo-Jnr, E. V., Ahmed, M. Z., \& Welch, J. J. (2015). The incidence of bacterial endosymbionts in terrestrial arthropods. Proceedings of Biology Science, 282, 20150249. https:// doi.org/10.1098/rspb.2015.0249.

Wolff, J. N., Gemmell, N. J., Tompkins, D. M., \& Dowling, D. K. (2017). Introduction of a maleharming mitochondrial haplotype via 'Trojan Females' achieves population suppression in fruit flies. eLife, 6, e23551. https://doi.org/10.7554/eLife.23551.

Wu, B., Luo, L., \& Gao, X. J. (2016). Cas9-triggered chain ablation of cas9 as a gene drive brake. Nature Biotechnology, 34, 137-138. https://doi.org/10.1038/nbt.3444.

Wright, O., Stan, G.-B., and Ellis, T. (2013). Building-in biosafety for synthetic biology. Microbiology, 159, Pt 7, 1221-1235. https://doi.org/10.1099/mic.0.066308-0.

Zentner, G. E., \& Wade, M. J. (2017). The promise and peril of CRISPR gene drives. BioEssays, 39, 1700109. https://doi.org/10.1002/bies.201700109.

Open Access This chapter is licensed under the terms of the Creative Commons Attribution 4.0 International License (http://creativecommons.org/licenses/by/4.0/), which permits use, sharing, adaptation, distribution and reproduction in any medium or format, as long as you give appropriate credit to the original author(s) and the source, provide a link to the Creative Commons license and indicate if changes were made.

The images or other third party material in this chapter are included in the chapter's Creative Commons license, unless indicated otherwise in a credit line to the material. If material is not included in the chapter's Creative Commons license and your intended use is not permitted by statutory regulation or exceeds the permitted use, you will need to obtain permission directly from the copyright holder.

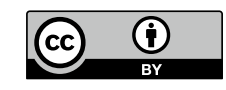

